\title{
TCEB3 is Regulated by Circ-00002/2/miR-I40-3p Axis to Promote the Progression of Cervical Cancer
}

Yufeng Wang'

Chuanhui Miao ${ }^{2}$

Xiang $\mathrm{Gao}^{3}$

'Department of Gynecology, Jinan Second Maternal and Child Health Hospital, Jinan, Shandong, 27II99, People's Republic of China; ${ }^{2}$ Department of Obstetrics and Gynecology, Shizhong District People's Hospital, Zaozhuang, Shandong, 277100, People's Republic of China; ${ }^{3}$ Department of Geratology, The First Affiliated Hospital of Weifang Medical University (Weifang People's Hospital), Weifang, Shandong, 26104I, People's Republic of China
Correspondence: Xiang Gao Department of Geratology, The First Affiliated Hospital of Weifang Medical University (Weifang People's Hospital), No. 15I, Guangwen Street, Kuiwen District, Weifang, Shandong, 26104I, People's Republic of China Email xianggaolI3@I26.com
Background: Cervical cancer is a common female malignancy, which accounts for a large proportion of cancer-related mortality in the world. Therefore, exploring the mechanisms of cervical cancer progression and seeking new therapeutic targets are extraordinarily needful. The aim of this study was to explore the role of TCEB3 in cervical cancer progression.

Methods: TCEB3 expression was detected in cervical cancer tissue and adjacent normal tissues using qRT-PCR and immunohistochemistry analysis. TCEB3 expression was measured in cells using Western blot and qRT-PCR assay. Flow cytometer, CCK-8, colony formation and transwell assays were used to detect cell apoptosis, viability, colonyforming ability and invasion of cervical cancer cells. The expression of Ki-67, MMP-2, and MMP-9 was detected using Western blot. Bioinformatics analysis was used to predict circRNA-miRNA and miRNA-mRNA interactions. RIP and luciferase reporter assay were used to determine the interaction relationship.

Results: TCEB3 expression was up-regulated in both cervical cancer tissues and cells. Silencing of TCEB3 inhibited cell proliferation and invasion and promoted apoptosis of cervical cancer cells. Additionally, silencing of TCEB3 reduced the protein expression of Ki67, MMP-2, and MMP-9 of cervical cancer cells. Mechanistically, we identified that TCEB3 was directly targeted gene of miR-140-3p, and circ-0000212 acted as a sponge of miR-140$3 p$. Moreover, TCEB3 was regulated by circ-0000212/miR-140-3p axis and played a tumor promotive role in cervical cancer.

Conclusion: Silencing of TCEB3 attenuated cell proliferation and invasion and promoted apoptosis of cervical cancer cells, and this effect was regulated by circ-0000212/miR-140-3p axis. Our findings may provide a novel promising target for cervical cancer treatment.

Keywords: cervical cancer, TCEB3, circ-0000212, miR-140-3p

\section{Introduction}

Cervical cancer acts as one of the most commonly malignant tumors, and it is the fourth leading cause of cancer-related deaths in women worldwide. ${ }^{1-4}$ Although the widespread application of human papillomavirus (HPV) vaccination and early screening programs have been used as effective strategies for disease prevention, the incidence rate of cervical cancer is increasing in developed and developing countries. $^{5}$ At present, the treatments of cervical cancer include surgery, chemotherapy, radiotherapy, and concurrent chemoradiotherapy therapy. ${ }^{6}$ However, cervical cancer still shows high invasion, which lead to the poor prognosis of patients. ${ }^{7}$ Therefore, it is essential to investigate the detailed mechanisms underlying 
progression of cervical cancer and identify novel and effective therapeutic targets for cervical cancer.

TCEB3 (also called Elongin A) is a transcriptionally active subunit of RNA polymerase II (Pol II) transcription factor Elongin (SIII), which accelerates the rate of Pol II elongation by inhibiting the transient pausing of the polymerase at many sites in the transcriptome. ${ }^{89}$ Elongin A-deficient mice showed a severely retarded development and generated an embryonic lethal phenotype, and mouse embryonic fibroblasts derived from the Elongin A-deficient mice display increased apoptosis and senescence-like growth defects. ${ }^{10}$ It has been reported that microsatellite mutations drive tumourigenesis and inactivate the tumour suppressors, and TCEB3 is one of the novel candidate driver genes that have more mutations than identical control repeats. ${ }^{11}$ Moreover, TCEB3 has been identified potential antigens associated with the pathogenesis of peripheral T-cell lymphomas. ${ }^{12}$ However, the expression and functions of TCEB3 in cervical cancer have not been investigated.

In recent years, circular RNA (circRNA), a novel type of non-coding RNA, has become a hotspot in a wide variety of human disease and cancers. ${ }^{13-19}$ Salmena et al have proposed a competitive endogenous RNA (ceRNA) hypothesis, which points out that mRNA, long non-coding RNAs (lncRNAs), and pseudogenes can competitively combine with microRNA (miRNA) to regulate gene expression. ${ }^{20}$ Since then, more and more evidences have shown that circRNA may act as ceRNAs through competitive binding with miRNA, thereby regulating the expression of downstream genes and participating in a series of biological processes involved in cancer (such as cell proliferation, invasion, and metastasis). ${ }^{21-23}$ However, the function of circRNAs in cervical cancer need to be further recognized.

In the present study, we investigated TCEB3 expression in cervical cancer tissues and cells. We assessed the effects of silencing of TCEB3 on cervical cancer cells through functional assays (including cell proliferation, invasion, and apoptosis). Moreover, we found that TCEB3 was regulated by circ-0000212/miR-140-3p axis and participated in the progression of cervical cancer, which might provide a novel target for future treatment of patients with cervical cancer.

\section{Materials and Methods}

\section{Patients and Specimens}

A total of 35 pairs of cervical cancer tissues and adjacent normal tissues were collected from patients with cervical cancer from January 2018 to December 2019 at our hospital. The inclusion criteria were: (1) The pathological diagnosis of the patients was cervical cancer; (2) The patients had no other malignancies; (3) all patients did not receive radiotherapy or chemotherapy before surgery. Patients who were not willing to cooperate with the treatment were excluded. After surgical resection, tissue specimens were stored at $-80^{\circ} \mathrm{C}$ for the further experiments. All patients signed informed consent forms. The study was conducted in accordance with the Declaration of Helsinki and approved by the Ethics Committee of our hospital (approval number: WFSRNYY2018-103-1).

\section{Cell Culture}

Human epidermal cell $(\mathrm{HaCaT})$ and cervical cancer cell lines (SiHa, HT-3, Hela, C33A) were purchased from Chinese Academy of Science (Shanghai, China). All cells were culture in DMEM medium (Invitrogen, Carlsbad, CA, USA) with $10 \%$ fetal bovine serum (FBS) and $1 \%$ penicillin-streptomycin (HyClone Laboratories, Inc., Logan, UT, USA) at $37{ }^{\circ} \mathrm{C}$ in an incubator with $5 \% \mathrm{CO}_{2}$.

\section{Cell Transfection}

$\mathrm{SiHa}$ and Hela cells $\left(3 \times 10^{5}\right.$ cells/well $)$ were seeded in a 6 -well plate. When the cells grew to $90 \%$ confluence, cells were transfected with a negative control of siRNATCEB3 (si-NC), siRNA targeting TCEB3 (si1-TCEB3 and si2-TCEB3), negative control of miR-140-3p inhibitor (inhibitor NC), miR-140-3p inhibitor (inhibitor), miR140-3p inhibitor+si1-TCEB3 (inhibitor+si1-TCEB3), negative control of siRNA-circ-0000212 (si-NC), siRNA targeting si-circ-0000212 (si1-circ and si2-circ) and si1circ + miR-140-3p inhibitor (sil-circ+inhibitor). Cell transfection was performed by Lipofectamine 3000 reagent (Invitrogen) according to the protocols provided by the manufacturer. After transfection for $48 \mathrm{~h}$, cells were harvested for the further experiments.

\section{Quantitative Real-Time Polymerase Chain Reaction (qRT-PCR)}

Total RNA was extracted from cells and tissues by TRIzol reagent (Invitrogen), then cDNA was synthesized using Primescript RT Reagent Kit (TaKaRa, Tokyo, Japan). QRT-PCR was carried out on StepOnePlus Real-Time PCR system (Applied Biosystems, Foster City, CA, USA) with SYBR Premix Ex Taq ${ }^{\mathrm{TM}}$ Reagent (TaKaRa). The relative expression levels was calculated using the 
$2^{-\Delta \Delta \mathrm{Ct}}$ method. GAPDH was employed as internal control. The PCR primers used in this study were as follow: TCEB3 (F: 5'-CTATGATGGCCCAAGCACCA-3', R: 5'ACATGCAACATGCAGTCCAC-3'), miR-140-3p (F: 5'TGGTACTGATGTGATGGACT-3', R: 5'-TCATATCACA CAGCACCGAT-3'), circ-0000212 (F: 5'-GGAGTT ACAGCGATCCAGGG-3', R: 5'-AGCTGACAAAGT GCTCTCCA-3') and GAPDH (F: 5'-CACCAT TGGCAATGAGCGGTTC-3'， R: 5'-AGGTCTTTGCGG ATGTCCACGT-3').

\section{Western Blot Analysis}

Total protein was extracted from cells using RIPA Lysis Buffer (Pierce, Rockford, IL, USA), and then protein concentration was detected by BCA Protein Assay Kit (Beyotime Biotechnology, Jiangsu, China). Subsequently, equal amount of protein $(20 \mu \mathrm{g})$ was separated by $10 \%$ sodium dodecyl sulfate polyacrylamide gel electrophoresis (SDS-PAGE) and transferred to polyvinylidene fluoride (PVDF) membrane (Millipore, Billerica, MA, USA). After blocking with $5 \%$ non-fat milk at $37^{\circ} \mathrm{C}$ for $1 \mathrm{~h}$, the membranes were incubated with primary antibodies [TCEB3, 3685; GAPDH (internal control), 5174; diluted at 1:1000; Cell Signaling Technology, USA. Ki67, ab92742; MMP-2, ab97779; MMP-9, ab76003; diluted at 1:1000, Abcam, UK] at $4^{\circ} \mathrm{C}$ overnight, and then incubated with HRP-labeled goat anti-rabbit IgG (diluted at 1:4000, Zhongshan Golden Bridge Biotechnology, Beijing, China) for $1 \mathrm{~h}$. Finally, an enhanced chemiluminescence (ECL) system (Millipore) was used to display protein bands, and the protein bands were analyzed by an Image-Pro Plus 6.0 system (Media Cybernetics, USA).

\section{Cell Counting Kit-8 (CCK-8) Assay}

The cell viability of cervical cancer was determined using Cell Counting kit-8 (CCK-8, Beyotime) according to manufacturer's instruction. Briefly, transfected cells $\left(3 \times 10^{3}\right.$ cells/well) were seeded into 96 -well plates and maintained for $0,24,48$, and $72 \mathrm{~h}$, respectively. At the indicated time point, cells were incubated with CCK-8 reagent $(10 \mu \mathrm{L})$ for additional $4 \mathrm{~h}$ at $37{ }^{\circ} \mathrm{C}$. Finally, the optical density (OD, $450 \mathrm{~nm}$ ) was detected by a microplate reader (BioRad, Philadelphia, PA, USA).

\section{Colony Formation Assay}

The transfected cells (500 cells/well) were seeded into 6-well plates and maintained in DMEM medium at $37^{\circ}$ $\mathrm{C}$ in an incubator with $5 \% \mathrm{CO}_{2}$. After 2 weeks, the cells were fixed with methanol and stained with $0.1 \%$ crystal violet (Sigma) for $20 \mathrm{~min}$. Finally, the colonies were imaged and counted under an EVOS M5000 microscope (Thermo Fisher Scientific, Pudong, Shanghai, China).

\section{Transwell Assay}

The transfected cells $\left(1 \times 10^{4}\right)$ were resuspended in $200 \mu \mathrm{L}$ serum-free medium and plated in the Matrigel-coated upper chamber (Corning, USA). Meanwhile, $600 \mu \mathrm{L}$ medium with $10 \%$ FBS was added to the lower chamber. After incubation for $48 \mathrm{~h}$, the non-invaded cells were removed with cotton swab, and the invasive cells were fixed with $4 \%$ polymethanol and then stained with $0.1 \%$ crystal violet for $20 \mathrm{~min}$. Finally, the cells that passed through the Matrigel were photographed and calculated in 5 randomly selected fields.

\section{Cell Apoptosis Analysis}

Cell apoptosis was detected using Annexin V-FITC/PI apoptosis detection kit (Beyotime). Briefly, the transfected cells $\left(1 \times 10^{6}\right.$ cells $)$ were resuspended in $200 \mu \mathrm{L}$ binding buffer, stained with $10 \mu \mathrm{L}$ of Annexin V-FITC for $15 \mathrm{~min}$ at room temperature in the dark, and then stained with 5 $\mu \mathrm{L}$ of propidium iodide (PI) for $5 \mathrm{~min}$ in the dark at room temperature. Finally, cell apoptosis was analyzed using a flow cytometer (BD Biosciences, San Jose, CA, USA).

\section{Dual-Luciferase Reporter Assay}

The TCEB3 wild type (TCEB3-WT), TCEB3 mutant (TCEB3-MUT), circ-0000212 wild type (circ-0000212WT), circ-0000212 mutant (circ-0000212-MUT) luciferase reporter plasmids, negative control of miR-140-3p mimic (mimic NC), and miR-140-3p mimic were constructed by Invitrogen. Cells were seeded on a 96-well plate and co-transfected with corresponding luciferase reporter plasmids and miR-140-3p mimic or its negative control. After transfection for $48 \mathrm{~h}$, luciferase activity was detected using the Dual-Luciferase Reporter Assay system (Promega, Madison, WI, USA).

\section{RNA Binding Protein}

\section{Immunoprecipitation (RIP) Assay}

SiHa and Hela cells were lysed with RNA immunoprecipitation lysis buffer (Millipore), then cell lysates were incubated with magnetic beads conjugated with negative control rabbit IgG or human anti-AGO2 antibody (Abcam, USA) at $4{ }^{\circ} \mathrm{C}$ overnight. Next, the samples were incubated with Proteinase $\mathrm{K}$ for $30 \mathrm{~min}$, and then immunoprecipitated 
RNA was extracted using Trizol. Finally, qRT-PCR was used to determine the relative expression of miR-140-3p and circ-0000212.

\section{Immunohistochemistry (IHC)}

Cervical cancer tissues and adjacent normal tissue were fixed in $10 \%$ neutral buffered formalin and embedded in paraffin. Next, $4 \mu \mathrm{m}$ thick sections of the tissues were cut, deparaffinized in xylene and rehydrated with graded alcohol. The sections were washed with phosphate buffered saline (PBS) and then boiled in citrate buffer ( $\mathrm{pH}$ 6.0) for $15 \mathrm{~min}$. The sections were incubated with $3 \% \mathrm{H}_{2} \mathrm{O}_{2}$ for 5 min to block the endogenous peroxidase activity and then incubated in goat serum to decrease nonspecific staining. The sections were incubated with anti-Elongin A antibody (ab246878, diluted at 1:200, Abcam) overnight at $4^{\circ} \mathrm{C}$, incubated with secondary antibody at $37^{\circ} \mathrm{C}$ for $20 \mathrm{~min}$ and then treated with DAB (Thermo Fisher Scientific) for $10 \mathrm{~min}$. The sections were counterstained with hematoxylin-eosin for $3 \mathrm{~min}$ and then dehydrated in ethanol. The positive staining of TCEB3 was yellow or brown color.

\section{Statistical Analysis}

All data were presented as mean \pm standard deviation (SD), and statistical analysis was performed by GraphPad Prism 7.0 (USA). Student's $t$-test was used to analyze the differences between two groups, and one-way ANOVA followed by Tukey's test was used to analyze the differences among multiple groups. All experiments in this study were carried out at least three times with triplicate samples. P value less than 0.05 was considered statistically significant.

\section{Results}

\section{TCEB3 is Up-Regulated in Cervical} Cancer Tissues and Cells

In order to explore the role of TCEB3 in the pathogenesis of cervical cancer, we first analyzed TCEB3 expression in cervical cancer based on GEPIA dataset and TCGA database. As shown in Figure 1A and B, compared with the normal group, TCEB3 expression was up-regulated in cervical squamous cell carcinoma and endocervical adenocarcinoma (CESC) and N1 stage. The overall survival rate of cervical cancer patients with low or high TCEB 3 expression was analyzed based on TCGA database. The result showed that patients with high TCEB3 expression had the lower survival rate than patients with low TCEB3 expression $(\mathrm{P}<0.01$, Figure $1 \mathrm{C})$. In addition, we analyzed TCEB3 expression in cervical cancer tissues using qRT-PCR and IHC analysis. Result showed that TCEB3 expression was up-regulated in cervical cancer tissues compared with adjacent normal tissues $(\mathrm{P}<0.01$, Figure 1D and $\mathrm{E})$. Subsequently, TCEB3 expression in cervical cancer cells was detected using qRT-PCR and Western blot analysis, which suggested that the mRNA and protein expression of TCEB3 in cervical cancer cells (SiHa, HT-3, Hela, C33A) was upregulated compared with $\mathrm{HaCaT}$ cells $(\mathrm{P}<0.01$, Figure $1 \mathrm{~F}$ and $\mathrm{G})$.

\section{Silencing of TCEB3 Attenuates Cell Proliferation and Invasion and Promoted Apoptosis of Cervical Cancer Cells}

To explore the biological function of TCEB3 in cervical cancer, SiHa and Hela cells which showed highest endogenous TCEB3 expression were transfected with si-TCEB3 for the loss-of-function experiments. As shown in Figure 2A, both si1-TCEB3 and si2-TCEB3 obviously decreased TCEB3 expression in SiHa and Hela cells $(\mathrm{P}<0.01)$. We then chose si1-TCEB3 for subsequent assays due to its highest inhibitory efficiency. Figure $2 \mathrm{~F}$ showed that si1-TCEB3 decreased TCEB3 protein expression in SiHa and Hela cells $(\mathrm{P}<0.01)$. CCK-8 assay showed that silencing of TCEB3 decreased the viability of $\mathrm{SiHa}$ and Hela cells $(\mathrm{P}<0.05$, Figure 2B). Consistently, cell colony assay confirmed the effects (Figure $2 \mathrm{C})$. Subsequently, transwell invasion assay showed that silencing of TCEB3 attenuated invasion ability of SiHa and Hela cells ( $\mathrm{P}<0.01$, Figure 2D). In addition, flow cytometric data showed that silencing of TCEB3 increased cell apoptosis in SiHa and Hela cells $(\mathrm{P}<0.01$, Figure $2 \mathrm{E})$. Besides, results of Western blot showed that silencing of TCEB3 decreased the protein expression of Ki-67, MMP-2, and MMP-9 ( $<<0.01$, Figure 2F).

\section{TCEB3 is Directly Targeted Gene of miR-140-3p in Cervical Cancer}

We next aimed to find the miRNAs that might be directly targeted TCEB3 in cervical cancer. By using bioinformatics tools (DGEs-DOWN and miRDB databases), we revealed that TCEB3 might be directly regulated by miR-140-3p (Figure $3 \mathrm{~A})$. The expression of miR-140-3p is generally low in various cancers (Figure 3B), and TCGA database showed that miR140-3p expression was down-regulated in cervical cancer tissues (Figure 3C), and patients with high miR-140-3p expression had the higher survival rate than patients with low miR140-3p expression (Figure 3D). Therefore, we chose miR-140$3 p$ for follow-up study. We analyzed miR-140-3p expression in cervical cancer tissues using qRT-PCR. As indicated in Figure 
A

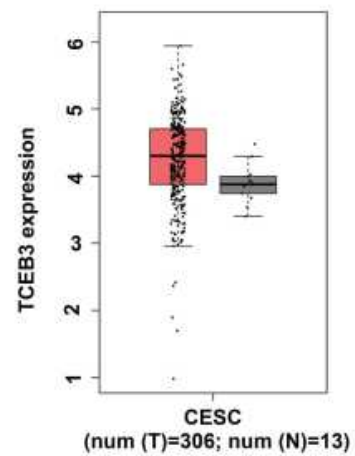

D

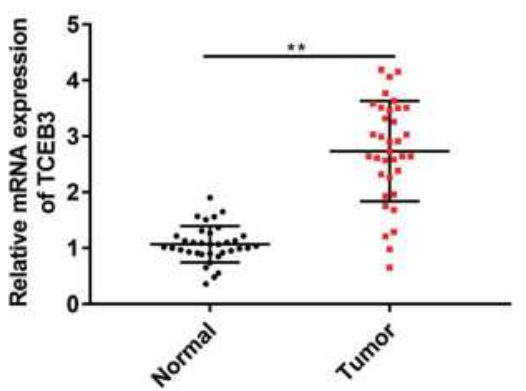

F

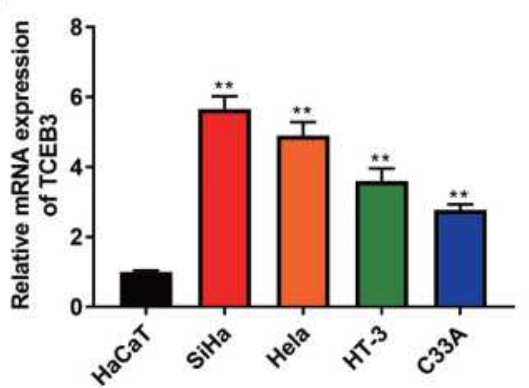

B

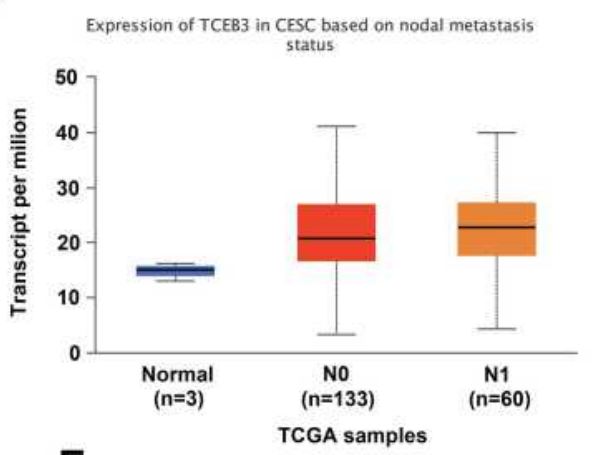

$\mathbf{E}$

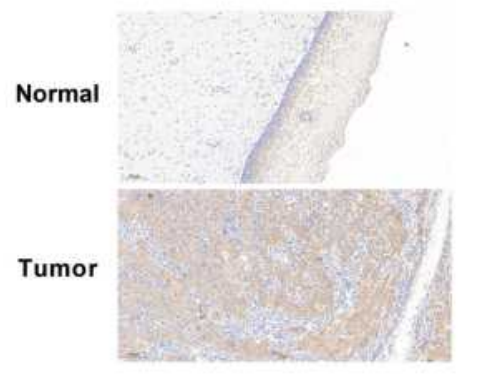

G

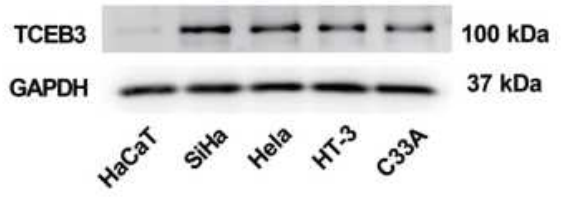

C
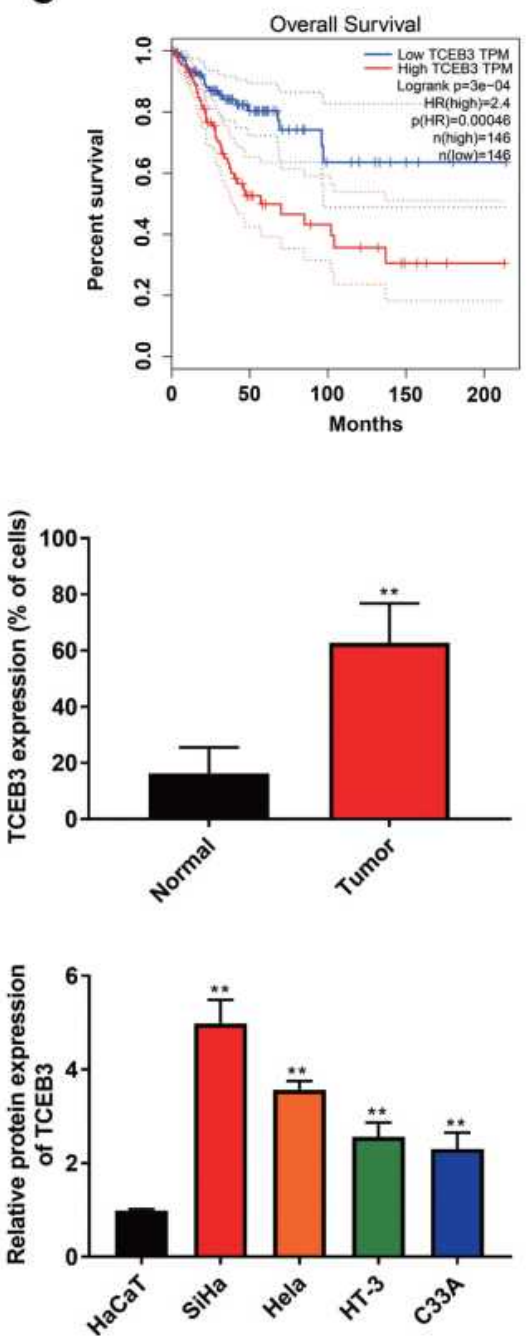

Figure I TCEB3 was up-regulated in cervical cancer tissues and cells. (A) TCEB3 expression in squamous cell carcinoma and endocervical adenocarcinoma (CESC) based on GEPIA dataset. (B) TCEB3 expression in CESC based on nodal metastasis status from TCGA database. (C) The overall survival rate of cervical cancer patients with low or high TCEB3 expression was analyzed based on TCGA database. (D) TCEB3 expression in cervical cancer tissues and adjacent normal tissues was detected using qRTPCR. (E) TCEB3 expression in cervical cancer tissues and adjacent normal tissues was detected using immunohistochemistry analysis. (F) TCEB3 expression in cervical cancer cells ( $\mathrm{SiHa}, \mathrm{HT}-3$, Hela, C33A) and human epidermal cell ( $\mathrm{HaCaT}$ ) was detected using qRT-PCR analysis. (G) TCEB3 expression in cervical cancer cells (SiHa, HT-3, Hela, $\mathrm{C} 33 \mathrm{~A})$ and human epidermal cell $(\mathrm{HaCaT})$ was detected using Western blot analysis. **P $<0.0 \mathrm{I}$.

3E, miR-140-3p expression was down-regulated in cervical cancer tissues compared with adjacent normal tissues $(\mathrm{P}<$ 0.01). Besides, to further verify the interaction between miR140-3p and TCEB3, we performed dual-luciferase reporter assays. Figure $3 \mathrm{~F}$ showed the binding site of miR-140-3p in the $3^{\prime}$-UTR of TCEB3. The results of luciferase reporter assay (Figure 3G) showed that miR-140-3p mimic obviously decreased the luciferase activity of TCEB3 wild type 3'UTR (TCEB3-WT) in SiHa and Hela cells $(\mathrm{P}<0.01)$, while there was no affection on the luciferase activity of TCEB3 mutant type 3'UTR (TCEB3-MT) in SiHa and Hela cells. Taken together, these data demonstrated that TCEB3 was directly targeted gene of miR-140-3p in cervical cancer.

\section{TCEB3 Reverses the Regulatory Effects of miR-I40-3p on Cell Proliferation, Invasion, and Apoptosis of Cervical Cancer Cells}

To further investigate the functional interaction between miR-140-3p and TCEB3 in the progression of cervical cancer, we transfected with miR-140-3p inhibitor and si-TCEB3 into $\mathrm{SiHa}$ and Hela cells to conduct the rescue experiments such as colony formation, transwell assay, and cell apoptosis analysis. As shown in Figure 4A, miR-140-3p expression in miR-140-3p inhibitor group was lower than that in inhibitor $\mathrm{NC}$ group $(\mathrm{P}<0.01)$, which indicated the transfection was 

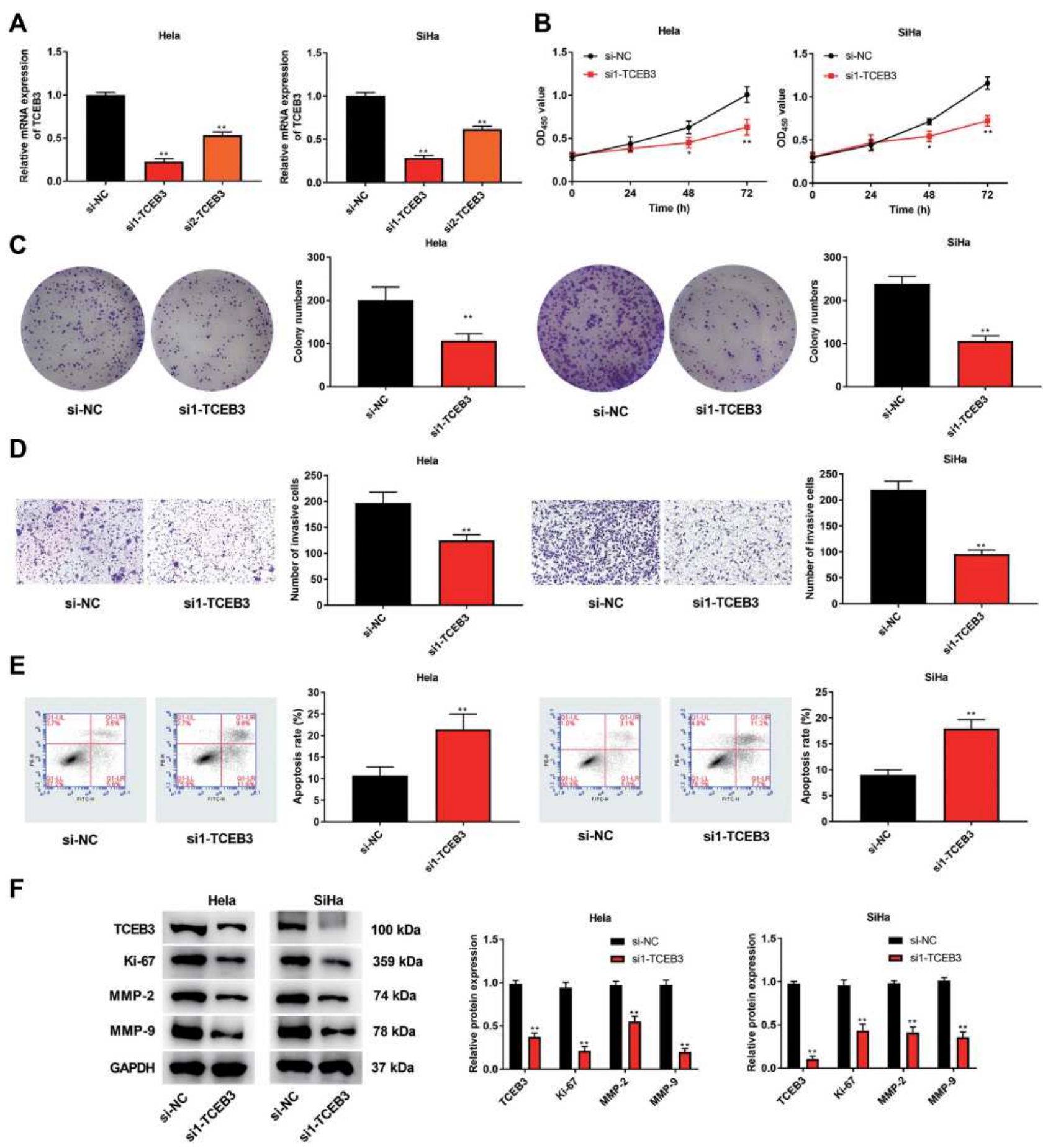

Figure 2 Silencing of TCEB3 attenuated cell proliferation and invasion and promoted apoptosis of cervical cancer cells. (A) TCEB3 expression in SiHa and Hela cells was detected using qRT-PCR analysis. (B) CCK-8 assay was used to detect the viability of $\mathrm{SiHa}$ and Hela cells. (C) Cell colony assay was used to detect cell proliferation in $\mathrm{SiHa}$ and Hela cells. (D) Transwell assay was used to detect cell invasion in $\mathrm{SiHa}$ and Hela cells. (E) Apoptosis of SiHa and Hela cells was analyzed using a flow cytometer. (F) The protein expression of TCEB3, Ki-67, MMP-2, and MMP-9 was detected using Western blot analysis. *P $<0.05$, **P $<0.01$.

successful. Subsequently, we found that low expression of miR-140-3p increased TCEB3 expression $(\mathrm{P}<0.01$, Figure $4 \mathrm{~B}$ and $\mathrm{F}$ ). In addition, low expression of miR-140-3p promoted cell proliferation and invasion and inhibited apoptosis of SiHa and Hela cells $(\mathrm{P}<0.01$, Figure $4 \mathrm{C}-\mathrm{E})$. Low expression of miR-140-3p increased the protein expression of Ki-67, MMP-2, and MMP-9 ( $\mathrm{P}<0.01$, Figure 4F). Furthermore, silencing of TCEB3 reversed the tumor promoting effects induced by miR-140-3p inhibitor $(\mathrm{P}<0.01$, Figure 4C-F). 
A

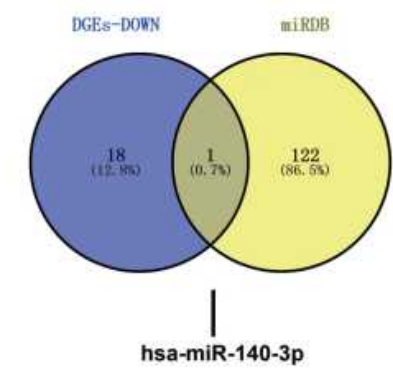

C

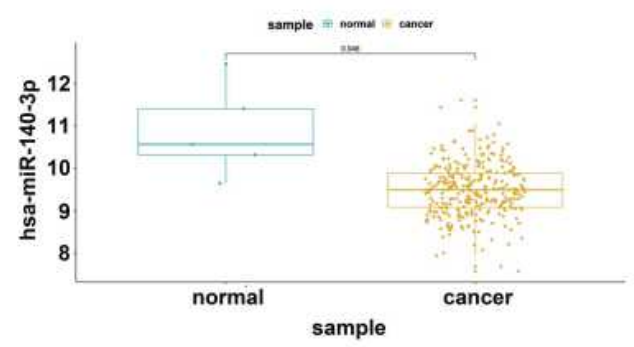

$\mathbf{F}$

TCEB3-WT 5'-CCAGUGGUUUUACCCUAUGGUAGG-3 , IIIIII miR-140-3p 3-GGCACCAAGAUGGGACACCAU- 5 TCEB3-MUT 5-CCAGUGGUUUAUGGGAUGGUAGG- 3 .

B

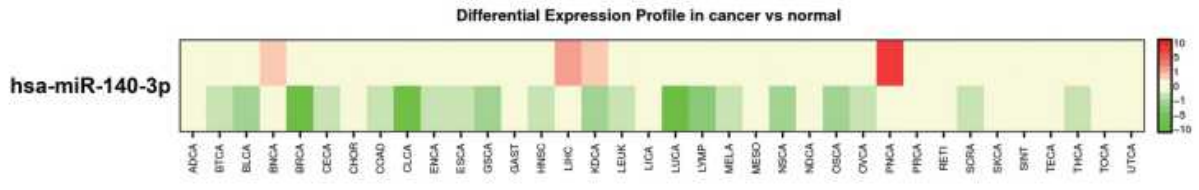

D

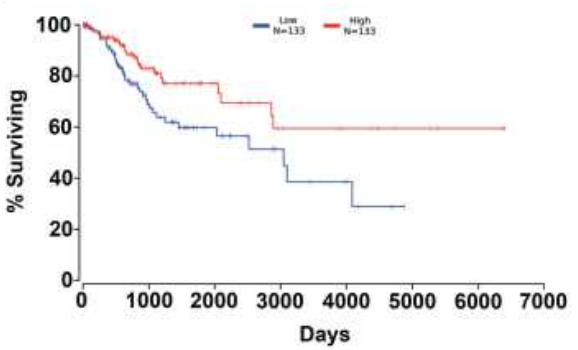

E

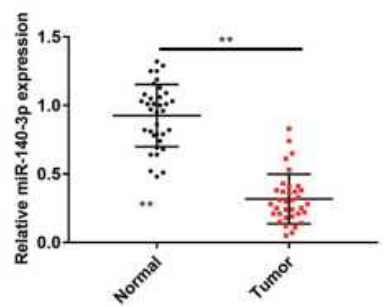

G
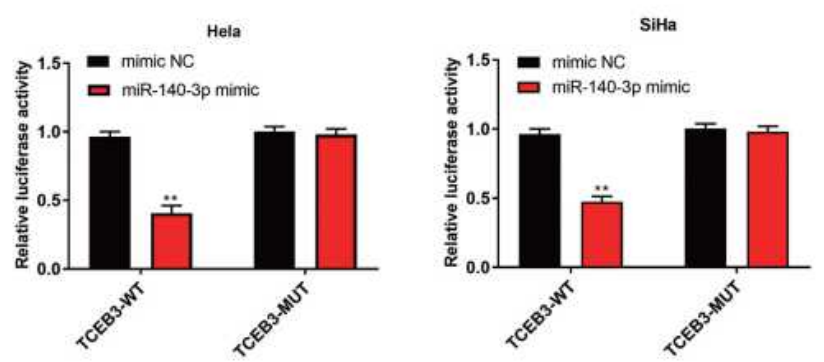

Figure 3 TCEB3 was directly targeted gene of miR-140-3p in cervical cancer. (A) The Venn diagram exhibited that TCEB3 might be regulated by miR-I40-3p predicted in DGEs-DOWN and miRDB databases. (B) dbDEMC database shows that miR-140-3p expression is generally low in various cancers. (C) miR-I40-3p expression in squamous cell carcinoma and endocervical adenocarcinoma (CESC) based on TCGA dataset. (D) The overall survival rate of cervical cancer patients with low or high miR-I40-3p expression was analyzed based on TCGA database. (E) miR-I40-3p expression in cervical cancer tissues and adjacent normal tissues was detected using qRT-PCR. (F) The putative-binding site of miR-I40-3p in the 3'-UTR of TCEB3. (G) Dual-luciferase reporter assay was performed to evaluate the interaction of TCEB3 and miR-I40-3p. **P < 0.01 .

\section{Circ-0000212 Acts as a Sponge of miR-I40-3p in Cervical Cancer}

It has been reported that circRNAs may play important roles in biological functions by sponging miRNAs. ${ }^{17}$ With the assistance of bioinformatics analysis (Target and DGEs), we found that miR-140-3p might be directly regulated by circ-0000212 (Figure 5A). Circ-0000212 expression in cervical cancer tissues was up-regulated based on the TCGA database (Figure 5B). Besides, we analyzed circ-0000212 expression in cervical cancer tissues using qRT-PCR. The results showed that circ-0000212 expression was up-regulated in cervical cancer tissues compared with adjacent normal tissues $(\mathrm{P}<0.01$, Figure 5C). Therefore, circ-0000212 was chosen as a follow-up subject. Dual-luciferase reporter assay was used to verify the interaction between circ-0000212 and miR-140-3p. Figure 5D showed the binding site of miR-140-3p in the 3'-UTR of circ-0000212. As shown in Figure 5E, miR140-3p mimic remarkably decreased the luciferase activity of circ-0000212-WT in SiHa and Hela cells, but miR-140$3 p$ mimic failed to influence the luciferase activity of circ0000212-MUT in both cells. Moreover, RIP assay was carried out to further verify the interaction between circ0000212 and miR-140-3p. As seen in Figure 5F, both circ0000212 and miR-140-3p were significantly enriched in compounds precipitated by anti-AGO2 antibody compared with IgG $(P<0.01)$, which proofed the interaction of miR$140-3 p$ with circ-0000212. 
A

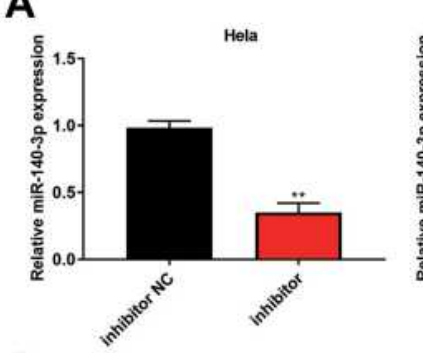

C

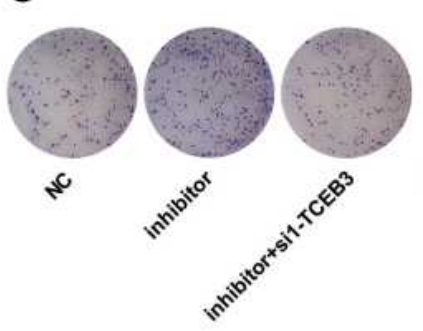

D

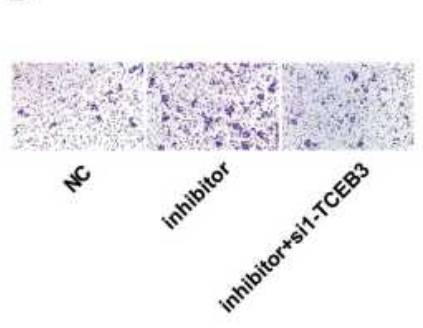

E

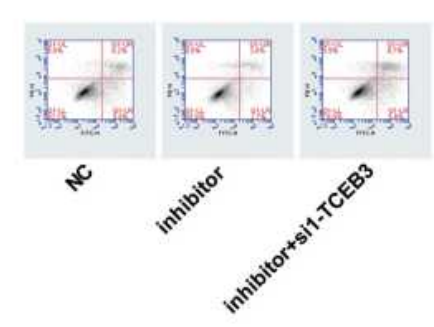

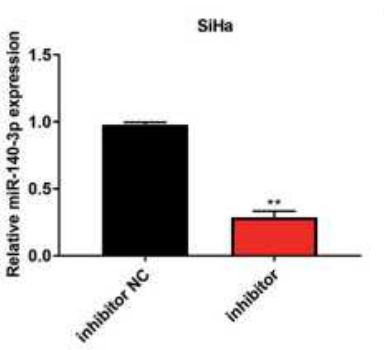
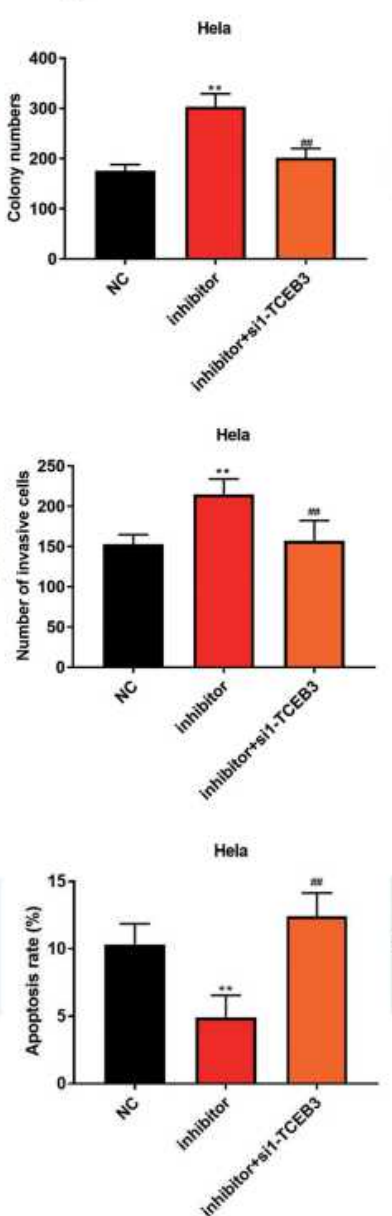

B
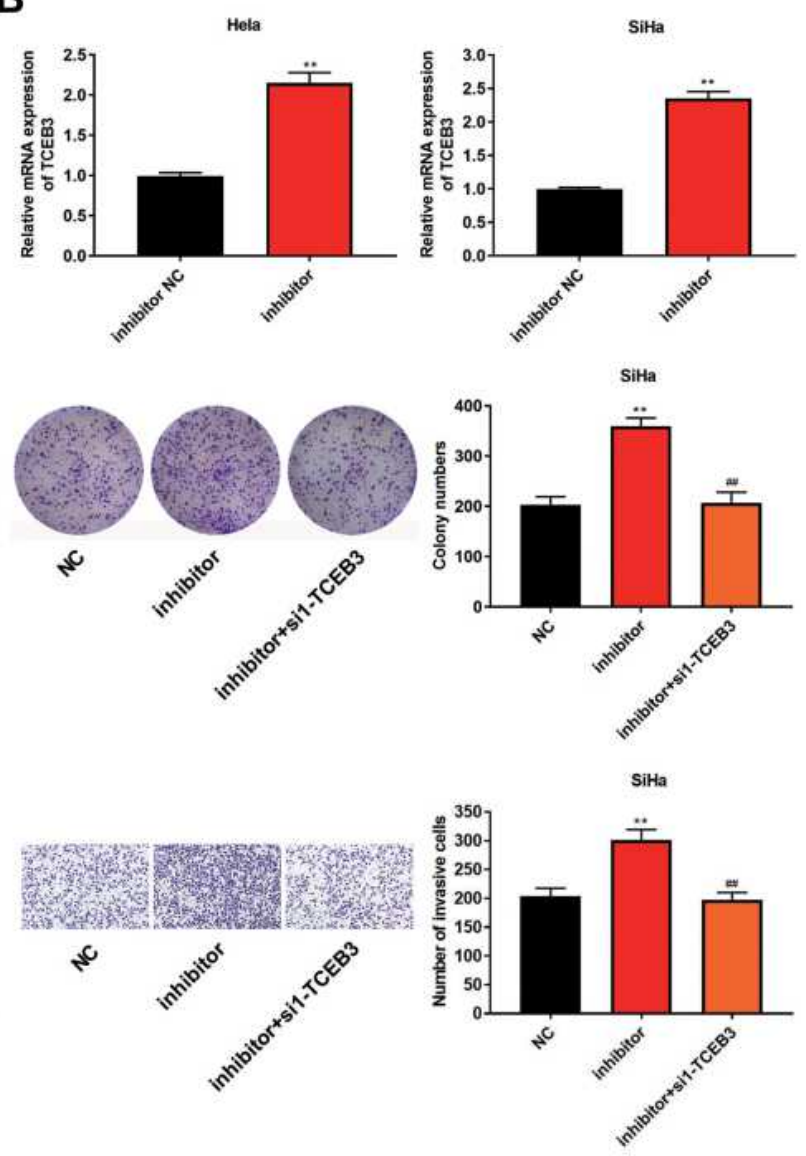

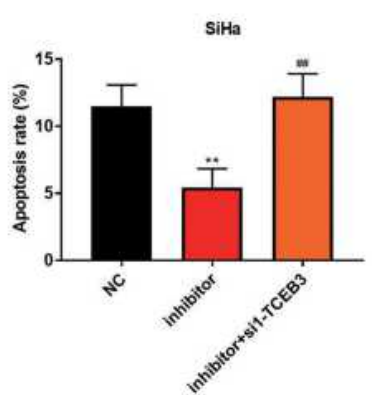

F
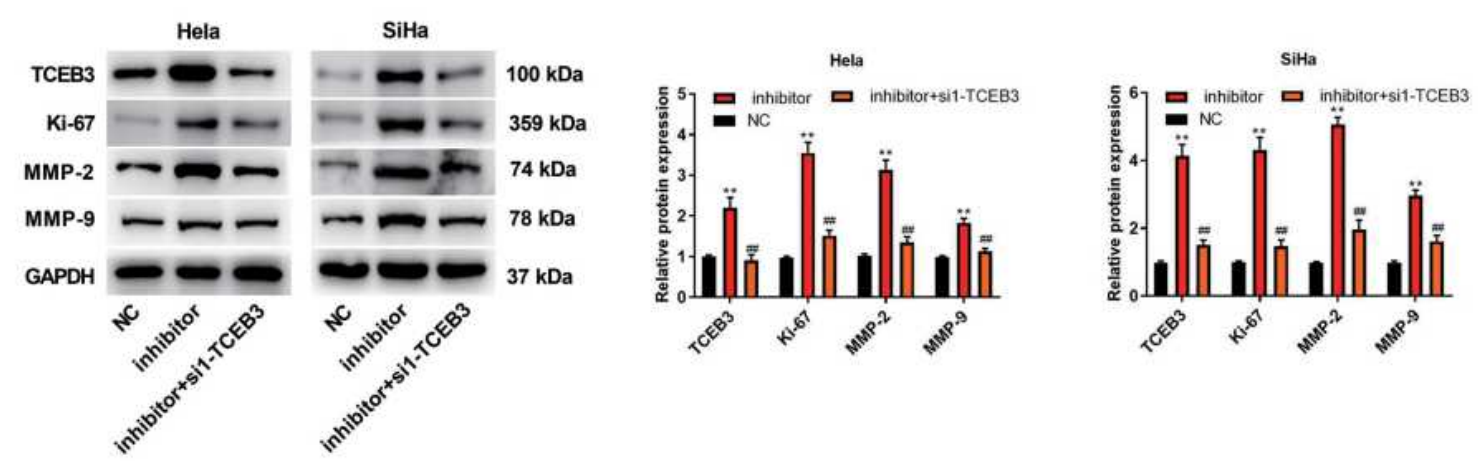

Figure 4 TCEB3 reversed the regulatory effects of miR-140-3p on cell proliferation, invasion, and apoptosis of cervical cancer cells. (A) miR-140-3p expression in SiHa and Hela cells was detected using qRT-PCR analysis. (B) TCEB3 expression in SiHa and Hela cells was detected using qRT-PCR analysis. (C) Cell colony assay was used to detect cell proliferation in SiHa and Hela cells. (D) Transwell assay was used to detect cell invasion in SiHa and Hela cells. (E) Apoptosis of SiHa and Hela cells was analyzed using a flow cytometer. (F) The protein expression of TCEB3, Ki-67, MMP-2, and MMP-9 was detected using Western blot analysis. ${ }^{* * P}<0.01$, ${ }^{\# P}<0.01$. 
A

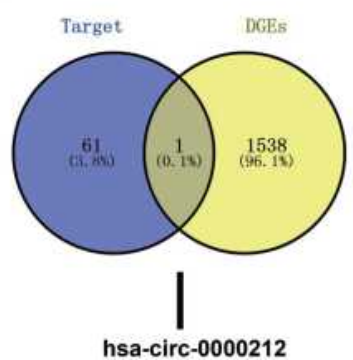

D

circ-0000212-WT 5'-AUAAUUUGGAAUAGCCUGUGGUU-3 II II | || miR-140-3p 3'-GGCACCAAGAUGGGACACCAU-5 circ-0000212-MUT 5'-AUAAUUUGGAAUAGCGACACCAU- 3 .
B

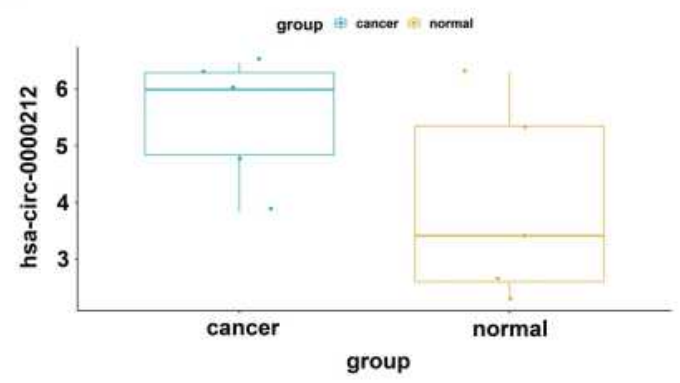

E

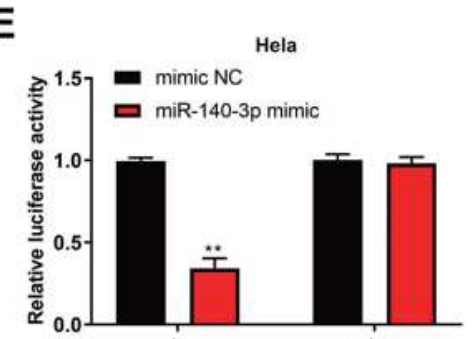

C
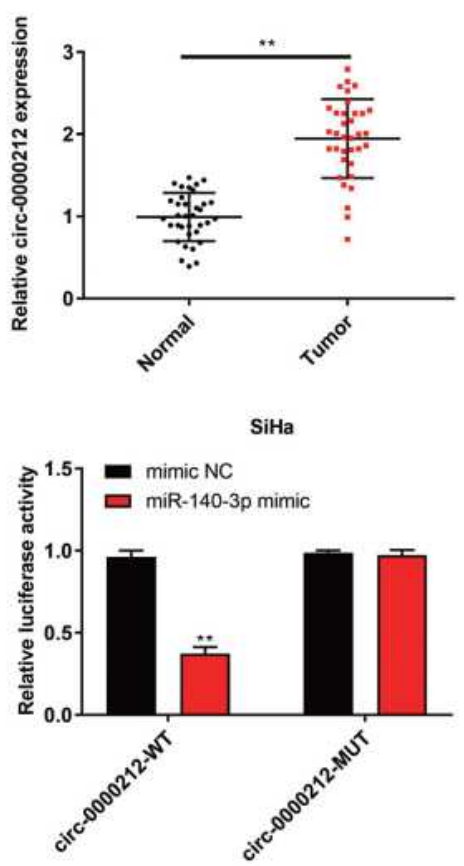

F

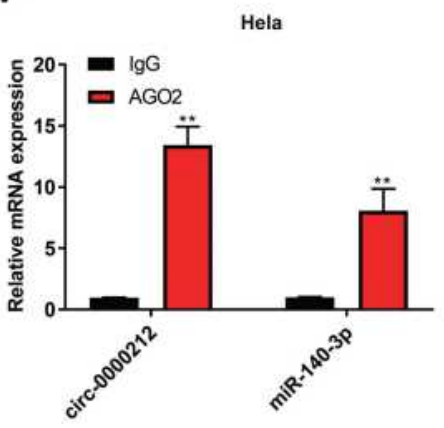

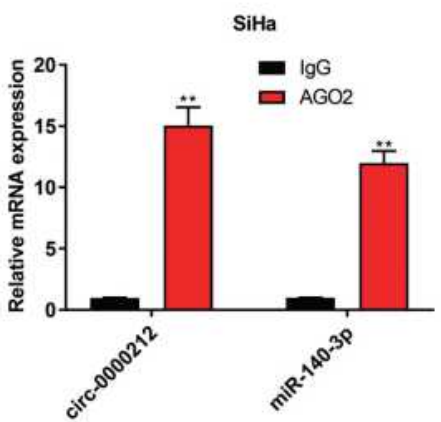

Figure 5 Circ-00002I2 acted as a sponge of miR-140-3p in cervical cancer. (A) The Venn diagram exhibited that miR-140-3p might be directly regulated by circ-00002I 2 predicted in Target and DGEs databases. (B) circ-00002I 2 expression in cervical cancer based on TCGA dataset. (C) circ-00002I 2 expression in cervical cancer tissues and adjacent normal tissues was detected using qRT-PCR. (D) The putative binding site of miR-I40-3p in the 3'-UTR of circ-00002I2. (E) Dual-luciferase reporter assay was performed to evaluate the interaction of circ-00002I 2 and miR-I40-3p. (F) RIP assay was performed in SiHa and Hela cells, followed by qRT-PCR to detect the expression of circ-00002I 2 and miR-140-3p. **P $<0.01$.

\section{miR-I40-3p Reverses the Regulatory Effects of Circ-00002I 2 on Cell Proliferation, Invasion, and Apoptosis of Cervical Cancer Cells}

To further explore whether circ-0000212 participates in the progression of cervical cancer through sponging miR-140-3p, we detected cell proliferation, invasion, and apoptosis of cervical cancer cells after co-transfection of miR-140-3p inhibitor and si-circ-0000212 into SiHa and Hela cells. The transfection efficiency of si-circ-0000212 was determined in $\mathrm{SiHa}$ and Hela cells ( $\mathrm{P}<0.01$, Figure $6 \mathrm{~A})$. Furthermore, silencing of sicirc-0000212 increased miR-140-3p expression, and inhibited cell proliferation and invasion and promoted apoptosis of $\mathrm{SiHa}$ and Hela cells $(\mathrm{P}<0.01$, Figure $6 \mathrm{~B}-\mathrm{E})$. Silencing of si-circ
-0000212 decreased the protein expression of Ki-67, MMP-2, and MMP-9 ( $\mathrm{P}<0.01$, Figure 6F). After the co-transfection of miR-140-3p inhibitor and si-circ-0000212, we found that miR-140-3p inhibitor reversed the tumor suppressive effects induced by silencing of circ-0000212 (P $<0.01$, Figure $6 \mathrm{~B}-\mathrm{F})$.

\section{Discussion}

A report on the global burden of cancer worldwide showed that there were nearly 570,000 new cases of cervical cancer in 2018, and more than 310,000 deaths attributed to cervical cancer. ${ }^{24}$ Although numerous researches have been performed to explore the pathogenesis of cervical cancer, the real effective target of cervical cancer is still unclear. $^{25,26}$ TCEB3 is the largest subunit of the elongin 
complex, which regulates the overall rate of Pol II elongation and takes part in ubiquitylation and degradation of Rpb1 following DNA damage. ${ }^{27,28}$ It has been reported that TCEB3 expression is up-regulated in myeloma cell lines (NCIH929, JJN3 and RPMI8226 cells). ${ }^{12}$ In addition, Kanno et al found that the most of the naive U87 cells and U87 glioma stem-like cells were Elongin A positive. ${ }^{29}$ However, the expression and functions of TCEB3 in cervical cancer remains largely unclear. In the present study, we found that TCEB3 expression was up-regulated in both cervical cancer tissues and cells, which indicated that TCEB3 played a vital role in the progression of cervical cancer.

More and more studies have shown that it is a highly complex process for the occurrence, development, and metastasis of cancer, epithelial-derived cells acquire malignant characteristics with high proliferative capacity and gradually augmented aggressiveness in the process. ${ }^{30,31}$ SiRNA technology has great potential in the treatment of currently incurable diseases (such as cancer), and has great potential in the use of targeted therapeutic drugs. ${ }^{32,33}$ In this study, to investigate the effects of TCEB3 in cervical cancer, SiHa and Hela cells were transfected with si-TCEB3 for the loss-of-function experiments. The results showed that silencing of TCEB3 decreased the viability, colony numbers, and invasion ability of $\mathrm{SiHa}$ and Hela cells. Moreover, silencing of TCEB3 decreased the protein expression of Ki-67, MMP-2, and MMP-9. Apoptosis is a process of programmed death and is an essential component of cell growth control. ${ }^{34}$ When disturbed, the imbalance between cell life and death may lead to tumor progression. ${ }^{35}$ Here, we found that silencing of TCEB3 increased cell apoptosis in $\mathrm{SiHa}$ and Hela cells. On the whole, our results suggested that silencing of TCEB3 inhibited cell proliferation and invasion and promoted apoptosis of cervical cancer cells.

It is well recognized that miRNAs can interact with the 3 '-UTR of target genes to regulate multiple target genes in the development, progression, and prognosis of various types of human cancer. ${ }^{36,37}$ Wang et al found that miR21 promoted the proliferation and migration of breast cancer cells by targeting LZTFL1. ${ }^{38} \mathrm{Li}$ et al reported that overexpression of miR-128 suppressed the cell proliferation and enhanced paclitaxel sensitivity in ovarian cancer cells by suppressing the expression of HOXB8. ${ }^{39} \mathrm{Lv}$ et al showed that miR-664 inhibited cell proliferation and induced apoptosis of cervical cancer cells via targeting c-Kit. ${ }^{40}$ In this study, to determine the mechanisms underlying the effects of TCEB3 in cervical cancer, we performed bioinformatics analysis to find the miRNAs that might be directly targeted TCEB3 in cervical cancer and eventually identified miR-140-3p. A study has illustrated that miR-140-3p expression is down-regulated in basal cell carcinoma compared with nonlesional skin. Consistent with previous study, we found that miR-140-3p expression was down-regulated in cervical cancer tissues. Subsequently, dual-luciferase reporter assays validated that miR-140-3p could directly binds to the $3^{\prime}$-UTR of TCEB3. Functionally, low expression of miR-140-3p promoted cell proliferation and invasion and inhibited apoptosis of SiHa and Hela cells. Low expression of miR-140-3p increased the protein expression of Ki-67, MMP-2, and MMP-9. However, silencing of TCEB3 reversed the tumor promoting effects induced by miR140-3p inhibitor. The above results indicated that TCEB3 was regulated by miR-140-3p to influence cell proliferation, invasion and apoptosis of cervical cancer cells.

A lot of studies suggest that circRNAs are able to serve as microRNAs sponge to regulate cervical cancer progression. For example, Chen et al reported that circMTO1 promoted tumorigenesis and chemoresistance of cervical cancer via regulating miR-6893. ${ }^{41} \mathrm{Wu}$ et al indicated that circAGFG1 promoted proliferation and migration of cervical cancer cells via miR-370-3p/RAF1 signaling. ${ }^{42}$ Based on these findings, we found that miR$140-3 p$ was directly regulated by circ-0000212 by RIP and dual-luciferase reporter assays. As we have seen, circ-0000212 (genomic location: chr10: 7405839-7423911) is a new circRNA in cervical cancer. TCGA database shows that circ-0000212 expression is up-regulated in cervical cancer tissues. Here, our results also showed that circ-0000212 expression was upregulated in cervical cancer tissues compared with adjacent normal tissues. Silencing of si-circ-0000212 increased miR-140-3p expression, inhibited cell proliferation and invasion and promoted apoptosis of SiHa and Hela cells. Silencing of si-circ-0000212 decreased the protein expression of $\mathrm{Ki}-67, \mathrm{MMP}-2$, and MMP-9. In addition, rescue experiments showed that miR-140-3p inhibitor reversed the tumor suppressive effects induced by silencing of circ-0000212. Overall, our results revealed that circ-0000212 might sponge miR-140-3p to regulate cell proliferation, invasion, and apoptosis of cervical cancer cells.

\section{Conclusion}

In conclusion, our findings demonstrated that TCEB3 expression was up-regulated in both cervical cancer tissues 
A

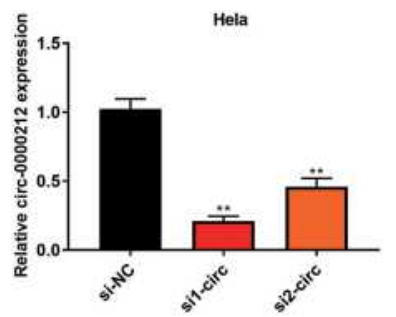

C

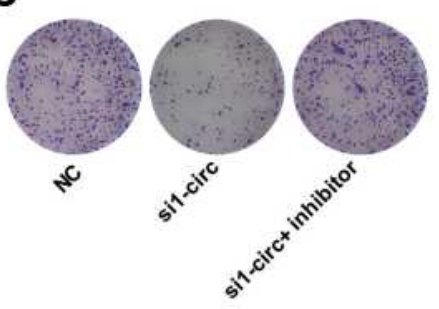

D

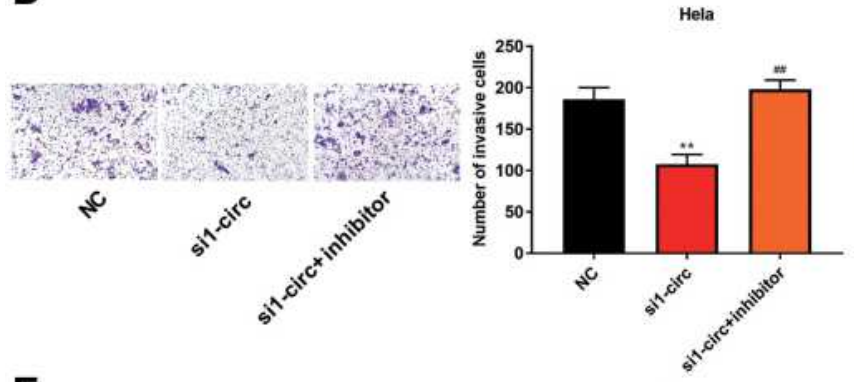

E

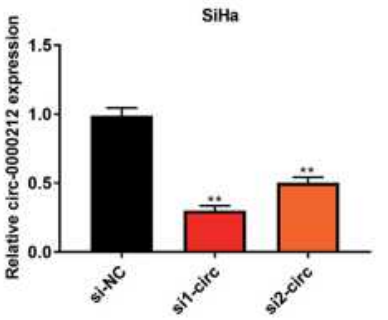

Hela
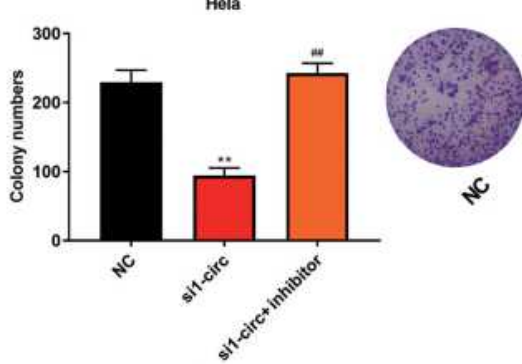

B
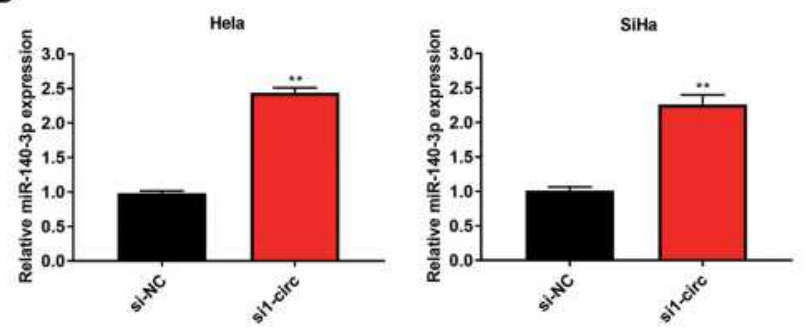

SiHa
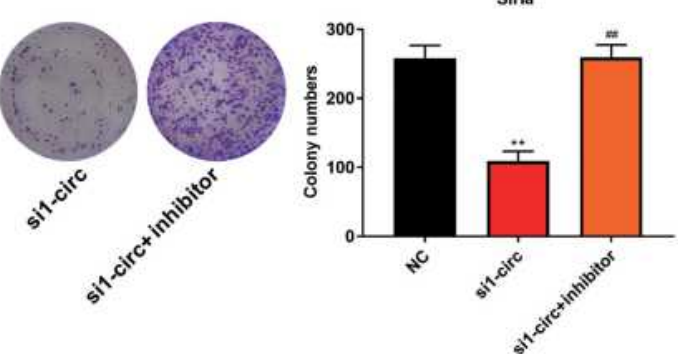

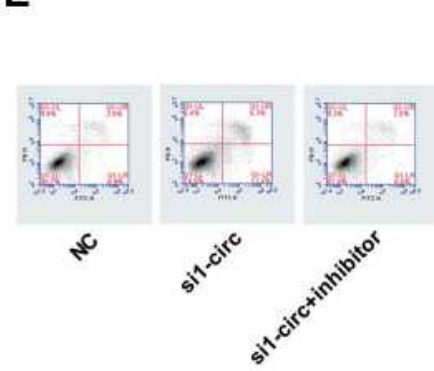

F

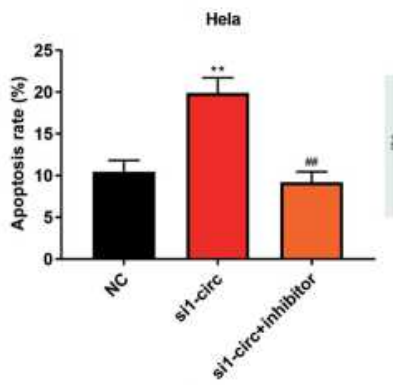

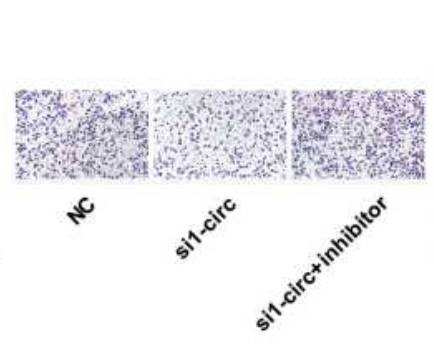
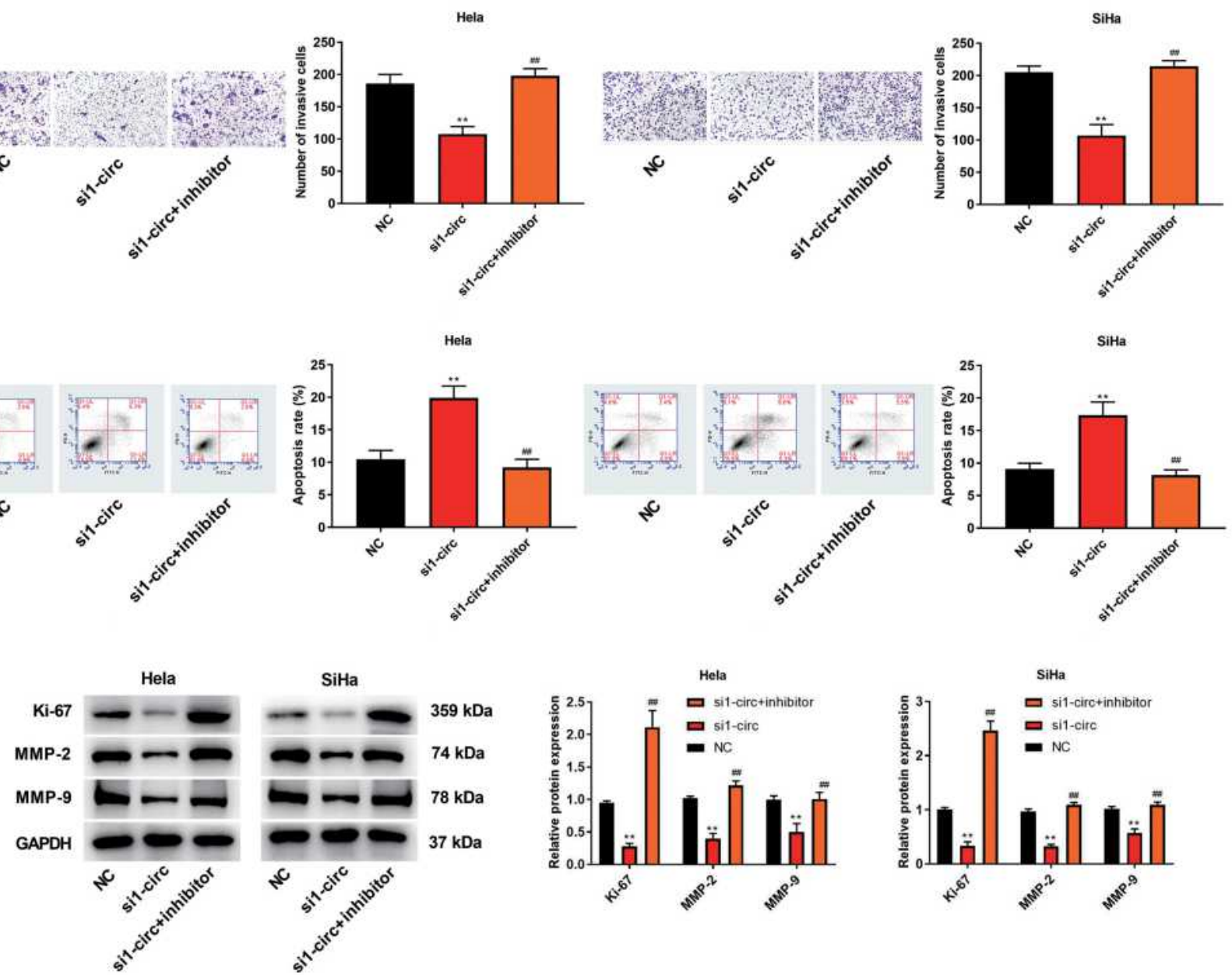

Figure 6 miR-140-3p reversed the regulatory effects of circ-00002/2 on cell proliferation, invasion, and apoptosis of cervical cancer cells. (A) Circ-00002। 2 expression in $\mathrm{SiHa}$ and Hela cells was detected using qRT-PCR analysis. (B) miR-140-3p expression in SiHa and Hela cells was detected using qRT-PCR analysis. (C) Cell colony assay was used to detect cell proliferation in $\mathrm{SiHa}$ and Hela cells. (D) Transwell assay was used to detect cell invasion in SiHa and Hela cells. (E) Apoptosis of SiHa and Hela cells was analyzed using a flow cytometer. (F) The protein expression of Ki-67, MMP-2, and MMP-9 was detected using Western blot analysis. ${ }^{* * P}<0.0 \mathrm{I}$, ${ }^{\#} \mathrm{P}<0.0 \mathrm{I}$. 
and cells. Moreover, TCEB3 was regulated by circ0000212/miR-140-3p axis and played a tumor promotive role in cervical cancer. Our findings may provide a novel insight into the therapy for cervical cancer.

\section{Data Sharing Statement}

The datasets used and analyzed during the current study are available from the corresponding author on reasonable request.

\section{Ethics Approval and Consent to Participate}

The protocol of this research was conducted in accordance with the Declaration of Helsinki and has been approved by the Ethics Committee of the First Affiliated Hospital of Weifang Medical University (approval number: WFSRNYY2018-103-1). All patients have signed written informed consent.

\section{Consent for Publication}

All authors have confirmed that the details of the article can be published, and agree to publish the content of the article.

\section{Acknowledgments}

Yufeng Wang and Chuanhui Miao are co-first authors.

\section{Funding}

This study was funded by Scientific research project plan of Weifang health and Family Planning Commission. (wfwsjs 2018-009).

\section{Disclosure}

No competing financial or other interests exist.

\section{References}

1. Nahand JS, Vandchali NR, Darabi H, et al. Exosomal microRNAs: novel players in cervical cancer. Epigenomics. 2020;12 (18):1651-1660. doi:10.2217/epi-2020-0026

2. Orbegoso C, Murali K, Banerjee S. The current status of immunotherapy for cervical cancer. Rep Pract Oncol Radiother. 2018;23 (6):580-588. doi:10.1016/j.rpor.2018.05.001

3. Torre LA, Islami F, Siegel RL, Ward EM, Jemal A. Global cancer in women: burden and trends. Cancer Epidemiol Biomarkers Prev. 2017;26(4):444-457. doi:10.1158/1055-9965.EPI-16-0858

4. Sadri nahand J, Moghoofei M, Salmaninejad A, et al. Pathogenic role of exosomes and microRNAs in HPV-mediated inflammation and cervical cancer: a review. Int $J$ Cancer. 2020;146(2):305-320. doi:10.1002/ijc. 32688

5. Kessler TA. Cervical cancer: prevention and early detection. Semin Oncol Nurs. 2017;33(2):172-183. doi:10.1016/j.soncn.2017.02.005
6. Fu ZZ, Peng Y, Cao LY, Chen YS, Li K, Fu BH. Value of apparent diffusion coefficient (ADC) in assessing radiotherapy and chemotherapy success in cervical cancer. Magn Reson Imaging. 2015;33 (5):516-524. doi:10.1016/j.mri.2015.02.002

7. Jhamad S, Aanjane R, Jaiswal S, Jain S, Bhagat P. Second primary cancer after radiotherapy for cervical cancer. J Midlife Health. 2018;9 (4):207-209. doi:10.4103/jmh.JMH_74_18

8. Aso T, Amimoto K, Takebayashi S, Okumura K, Hatakeyama M. Structural organization and chromosome location of the mouse elongin A gene (Tceb3). Cytogenet Cell Genet. 1999;86(3-4):259-262. doi:10.1159/000015355

9. Weems JC, Slaughter BD, Unruh JR, et al. Cockayne syndrome $\mathrm{B}$ protein regulates recruitment of the Elongin A ubiquitin ligase to sites of DNA damage. J Biol Chem. 2017;292(16):6431-6437. doi:10.1074/jbc.C117.777946

10. Miyata K, Yasukawa T, Fukuda M, et al. Induction of apoptosis and cellular senescence in mice lacking transcription elongation factor, Elongin A. Cell Death Differ. 2007;14(4):716-726. doi:10.1038/sj. cdd. 4402067

11. Alhopuro P, Sammalkorpi H, Niittymäki I, et al. Candidate driver genes in microsatellite-unstable colorectal cancer. Int $J$ Cancer. 2012;130(7):1558-1566. doi:10.1002/ijc.26167

12. Cooper CD, Lawrie CH, Liggins AP, et al. Identification and characterization of peripheral T-cell lymphoma-associated SEREX antigens. PLoS One. 2011;6(8):22. doi:10.1371/journal.pone.0023916

13. Shabaninejad Z, Vafadar A, Movahedpour A, et al. Circular RNAs in cancer: new insights into functions and implications in ovarian cancer. J Ovarian Res. 2019;12(1):019-0558. doi:10.1186/s13048-019-0558-5

14. Naeli P, Pourhanifeh MH, Karimzadeh MR, et al. Circular RNAs and gastrointestinal cancers: epigenetic regulators with a prognostic and therapeutic role. Crit Rev Oncol Hematol. 2020;145(102854):20.

15. Abbaszadeh-Goudarzi K, Radbakhsh S, Pourhanifeh MH, et al. Circular RNA and diabetes: epigenetic regulator with diagnostic role. Curr Mol Med. 2020;20(7):516-526. doi:10.2174/ 1566524020666200129142106

16. Yousefi F, Shabaninejad Z, Vakili S, et al. TGF- $\beta$ and WNT signaling pathways in cardiac fibrosis: non-coding RNAs come into focus. Cell Commun Signal. 2020;18(1):020-00555. doi:10.1186/s12964-02000555-4

17. Hong H, Zhu H, Zhao S, et al. The novel circCLK3/miR-320a/ FoxM1 axis promotes cervical cancer progression. Cell Death Dis. 2019;10(12):019-2183. doi:10.1038/s41419-019-2183-Z

18. Chen LL. The biogenesis and emerging roles of circular RNAs. Nat Rev Mol Cell Biol. 2016;17(4):205-211. doi:10.1038/nrm.2015.32

19. Nahand JS, Jamshidi S, Hamblin MR, et al. Circular RNAs: new epigenetic signatures in viral infections. Front Microbiol. 2020;11 (1853). doi:10.3389/fmicb.2020.01853

20. Salmena L, Poliseno L, Tay Y, Kats L, Pandolfi PP. A ceRNA hypothesis: the Rosetta stone of a hidden RNA language? Cell. 2011;146(3):353-358. doi:10.1016/j.cell.2011.07.014

21. Lu Q, Liu T, Feng H, et al. Circular RNA circSLC8A1 acts as a sponge of miR-130b/miR-494 in suppressing bladder cancer progression via regulating PTEN. Mol Cancer. 2019;18(1):019-1040. doi:10.1186/s12943-019-1040-0

22. Bi W, Huang J, Nie C, et al. CircRNA circRNA_102171 promotes papillary thyroid cancer progression through modulating CTNNBIP1dependent activation of $\beta$-catenin pathway. J Exp Clin Cancer Res. 2018;37(1):018-0936. doi:10.1186/s13046-018-0936-7

23. Song T, Xu A, Zhang Z, et al. CircRNA hsa_circRNA_101996 increases cervical cancer proliferation and invasion through activating TPX2 expression by restraining miR-8075. J Cell Physiol. 2019;234(8):14296-14305. doi:10.1002/jcp.28128

24. Bray F, Ferlay J, Soerjomataram I, Siegel RL, Torre LA, Jemal A. Global cancer statistics 2018: GLOBOCAN estimates of incidence and mortality worldwide for 36 cancers in 185 countries. CA Cancer J Clin. 2018;68(6):394-424. doi:10.3322/caac.21492 
25. Ghasemi F, Shafiee M, Banikazemi Z, et al. Curcumin inhibits NF-kB and Wnt/ $\beta$-catenin pathways in cervical cancer cells. Pathol Res Pract. 2019;215(10):23. doi:10.1016/j.prp.2019.152556

26. Nahand JS, Taghizadeh-Boroujeni S, Karimzadeh M, et al. microRNAs: new prognostic, diagnostic, and therapeutic biomarkers in cervical cancer. $J$ Cell Physiol. 2019;234(10):17064-17099. doi:10.1002/jcp. 28457

27. Yasukawa T, Kamura T, Kitajima S, Conaway RC, Conaway JW, Aso T. Mammalian Elongin A complex mediates DNA-damageinduced ubiquitylation and degradation of Rpb1. EMBO J. 2008;27 (24):3256-3266. doi:10.1038/emboj.2008.249

28. Gerber M, Eissenberg JC, Kong S, et al. In vivo requirement of the RNA polymerase II elongation factor elongin A for proper gene expression and development. Mol Cell Biol. 2004;24 (22):9911-9919. doi:10.1128/MCB.24.22.9911-9919.2004

29. Kanno H, Sato H, Yokoyama TA, Yoshizumi T, Yamada S. The VHL tumor suppressor protein regulates tumorigenicity of U87-derived glioma stem-like cells by inhibiting the JAK/STAT signaling pathway. Int $J$ Oncol. 2013;42(3):881-886. doi:10.3892/ ijo.2013.1773

30. Eccles SA, Welch DR. Metastasis: recent discoveries and novel treatment strategies. Lancet. 2007;369(9574):1742-1757. doi:10.1016/S0140-6736(07)60781-8

31. Gupta GP, Massagué J. Cancer metastasis: building a framework. Cell. 2006;127(4):679-695. doi:10.1016/j.cell.2006.11.001

32. Singh A, Trivedi P, Jain NK. Advances in siRNA delivery in cancer therapy. Artif Cells Nanomed Biotechnol. 2018;46(2):274-283. doi:10.1080/21691401.2017.1307210

33. Shajari N, Mansoori B, Davudian S, Mohammadi A, Baradaran B. Overcoming the challenges of siRNA delivery: nanoparticle strategies. Curr Drug Deliv. 2017;14(1):36-46. doi:10.2174/ 1567201813666160816105408
34. Koff JL, Ramachandiran S, Bernal-Mizrachi L. A time to kill: targeting apoptosis in cancer. Int J Mol Sci. 2015;16(2):2942-2955. doi:10.3390/ijms 16022942

35. Redza-Dutordoir M, Averill-Bates DA. Activation of apoptosis signalling pathways by reactive oxygen species. Biochim Biophys Acta. 2016;12(10):17.

36. Bai N, Peng E, Qiu X, et al. circFBLIM1 act as a ceRNA to promote hepatocellular cancer progression by sponging miR-346. J Exp Clin Cancer Res. 2018;37(1):018-0838. doi:10.1186/s13046-018-0838-8

37. Xu L, Feng X, Hao X, et al. CircSETD3 (Hsa_circ_0000567) acts as a sponge for microRNA-421 inhibiting hepatocellular carcinoma growth. J Exp Clin Cancer Res. 2019;38(1):019-1041. doi:10.1186/ s13046-019-1041-2

38. Wang $\mathrm{H}$, Tan $\mathrm{Z}$, $\mathrm{Hu} \mathrm{H}$, et al. microRNA-21 promotes breast cancer proliferation and metastasis by targeting LZTFL1. BMC Cancer. 2019;19(1):019-5951.

39. Li R, Gong L, Li P, Wang J, Bi L. MicroRNA-128/homeobox B8 axis regulates ovarian cancer cell progression. Basic Clin Pharmacol Toxicol. 2019;125(6):499-507. doi:10.1111/bcpt.13288

40. Lv M, Ou R, Zhang Q, et al. MicroRNA-664 suppresses the growth of cervical cancer cells via targeting c-Kit. Drug Des Devel Ther. 2019;13:2371-2379. doi:10.2147/DDDT.S203399

41. Chen M, Ai G, Zhou J, Mao W, Li H, Guo J. circMTO1 promotes tumorigenesis and chemoresistance of cervical cancer via regulating miR-6893. Biomed Pharmacother. 2019;117(109064):18. doi:10.1016/j.biopha.2019.109064

42. Wu F, Zhou J. CircAGFG1 promotes cervical cancer progression via miR-370-3p/RAF1 signaling. BMC Cancer. 2019;19(1):019-6269. doi:10.1186/s12885-019-6269-x
OncoTargets and Therapy

\section{Publish your work in this journal}

OncoTargets and Therapy is an international, peer-reviewed, open access journal focusing on the pathological basis of all cancers, potential targets for therapy and treatment protocols employed to improve the management of cancer patients. The journal also focuses on the impact of management programs and new therapeutic

Submit your manuscript here: https://www.dovepress.com/oncotargets-and-therapy-journ agents and protocols on patient perspectives such as quality of life, adherence and satisfaction. The manuscript management system is completely online and includes a very quick and fair peer-review system, which is all easy to use. Visit http://www.dovepress.com/ testimonials.php to read real quotes from published authors. 